DOI: 10.22630/EIOGZ.2014.107.25

Zeszyty Naukowe Szkoły Głównej Gospodarstwa Wiejskiego

Ekonomika i Organizacja Gospodarki Żywnościowej nr 107, 2014: 57-67

Krystyna Krzyżanowska

Katedra Ekonomiki Edukacji, Komunikowania i Doradztwa

Szkoła Główna Gospodarstwa Wiejskiego w Warszawie

\title{
Tendencje zmian w działaniach informacyjno- -promocyjnych w turystyce wiejskiej i ich skuteczność
}

\section{Wstęp}

Turystyka na terenach wiejskich nie jest nowym sposobem spędzania wolnego czasu. W początkowej fazie rozwoju traktowana była jako wypoczynek dla najbogatszych klas społecznych. Wyjazdy i pobyty na terenach wiejskich znane były arystokracji europejskiej, a jazda konna, łowienie ryb, polowania czy korzystanie z dobrej kuchni wiejskiej należało do dobrych zachowań. Również posiadanie letniej rezydencji zlokalizowanej na obszarach wiejskich nobilitowało jej właściciela [Zawadka 2010, s. 17]. Tradycja wypoczynku na wsi sięga początku XIX wieku. W przeszłości wyjazd na wieś głównie związany był z odwiedzinami u rodziny i przyjaciół tam mieszkających, a także z „letniskami”, na które wyjeżdżali bardziej zamożni mieszkańcy miast, głównie inteligencja. Począwszy od lat 60. przybrała ona postać tzw. wczasów pod gruszą organizowanych przez różne zakłady pracy oraz biuro turystyczne „Gromada”. Obecnie turystyka wiejska/agroturystyka jako zorganizowana i prawnie usankcjonowana forma turystyki zaczyna przybierać bardziej skomercjalizowane formy. Obejmuje bowiem odpłatne wynajmowanie kwater letniskowych, organizowanie wyżywienia oraz świadczenie różnorodnych usług towarzyszących. Agroturystyka w takiej formie pozwala rodzinom rolniczym na uzyskanie dodatkowych dochodów, co jest szczególnie ważne w obecnej, bardzo trudnej sytuacji polskiego rolnictwa. Oprócz tego stwarza nowe możliwości użytkowe przestrzeni wiejskiej, zabudowań rolniczych i lokalnej infrastruktury. 
Aktualny stan agroturystyki w Polsce odbiega znacznie od poziomu jej rozwoju w innych krajach Europy Zachodniej, mimo iż w ostatnich latach obserwuje się znaczny wzrost liczby gospodarstw świadczących usługi w tym zakresie. W 1993 roku gospodarstw agroturystycznych w Polsce było około 1 tys. [MR i RW 2005], gdy tymczasem w 2012 roku ich liczba wzrosła do 7,6 tys. [Raport 2013, s. 92], co stanowi tylko 0,5\% ogólnej liczby gospodarstw rolniczych w Polsce ${ }^{1}$ (dla porównania w Wielkiej Brytanii 10,0\%, a w Austrii 8,0\%).

Tempo rozwoju turystyki wiejskiej/agroturystyki uzależnione jest w dużym stopniu od systemu marketingu, który obejmuje przygotowanie produktu turystycznego, wskazuje sposoby jego sprzedaży oraz wykorzystywane do tego celu kanały dystrybucji, a także organizuje działania promocyjne.

Współcześnie, w warunkach dynamicznie zmieniającego się rynku i rosnącej konkurencji, coraz więcej turystów, podejmując decyzję o wyborze miejsc wypoczynku i celach podróży, zaczyna interesować się poszczególnymi oferentami i ich działaniami. Publiczne zainteresowanie funkcjonowaniem strony podażowej na rynku usług turystycznych wpływa na podejmowanie działań z zakresu budowania pozytywnego wizerunku wsi i regionów. Przynosi również wiele korzyści zarówno właścicielom takich gospodarstw, jak i samym turystom [Tew i Barbieri 2012, s. 215-224, Flaningan, Blackstock, Hunter 2014, s. 394-405]. Kluczowymi narzędziami wykorzystywanymi w komunikacji marketingowej dotyczącej turystyki wiejskiej są: portale i strony internetowe, imprezy wystawiennicze, targi, evanty i różne materiały drukowane.

\section{Cel i metodyka badań}

Celem opracowania było przedstawienie tendencji zmian w zakresie form promocji stosowanych przez usługodawców i źródeł informacji preferowanych przez klientów odpoczywających na wsi w latach 1997-2013, a także ocena stopnia dostosowania działań informacyjno-promocyjnych z zakresu turystyki wiejskiej/agroturystyki podejmowanych przez usługodawców do potrzeb i oczekiwań turystów. W artykule wykorzystane zostały wyniki badań empirycznych przeprowadzonych zarówno przez autorkę, jak i innych autorów z różnych ośrodków naukowych w Polsce, dane wtórne pochodzące z ekspertyz wykonanych przez różne instytucje oraz literatura przedmiotu. Do opracowania wyników badań zastosowano metodę analizy porównawczej.

\footnotetext{
${ }^{1}$ Według danych GUS w 2012 roku w Polsce funkcjonowało 1543,5 tys. gospodarstw rolniczych, www.farmer.pl/fakty/polska/w-polsce-sa-373-gospodarstwa-posiadajace-ponad-tysiac-ha, 40756. html (data dostępu: 24.02.2014).
} 


\section{Promocja turystyki wiejskiej w literaturze}

Promocja, obok produktu, ceny, dystrybucji, jest integralnym elementem marketingu, bez którego skuteczność i efektywność wysiłków marketingowych podejmowanych przez przedsiębiorstwa nie osiagnę̧aby pożądanego poziomu. Nie wystarczy bowiem zaprojektować użyteczną usługę dostosowaną do potrzeb klientów, znaleźć dla niej odpowiednie kanały dystrybucji i ustalić cenę adekwatną do warunków rynkowych, aby ją sprzedać. Współczesny, bardzo konkurencyjny rynek wymusza na podmiotach gospodarczych podejmowanie działań promocyjnych, bez których nawet bardzo atrakcyjne oferty nie mogłyby zaistnieć wśród konkurencyjnych propozycji i dotrzeć do świadomości potencjalnych nabywców. Właśnie temu służy promocja, która kształtuje świadomość istnienia oferty oraz dostarcza nabywcom informacji [Jaremen 2013, s. 151].

W literaturze przedmiotu promocję definiuje się w ujęciu czynnościowym (funkcjonalnym) lub rzeczowym (instrumentalnym). W pierwszym aspekcie przez promocję rozumie się każde osobowe lub bezosobowe działanie nakłaniające do kupna produktu albo do zachowania zgodnego z wolą i ideą sprzedającego [Stanton 1975, s. 467]. W ujęciu rzeczowym przez promocję rozumie się najczęściej zespół skoordynowanych, taktycznych i strategicznych działań i środków komunikacji, za pomocą których przedsiębiorstwo przekazuje na rynek informacje i w ten sposób kształtuje przychylną opinię o sobie i swoich produktach, co w konsekwencji ma motywować potencjalnych i aktualnych nabywców do zakupów [Sikora 2012, s. 177, Sikora 2013, s. 72]. Jest to dość ogólne ujęcie, które można odnieść do każdego produktu i każdego przedsiębiorstwa, a także do bardzo zróżnicowanych środków, narzędzi i sposobów promowania. W definicji tej pojawia się termin komunikacja, co ma akcentować, że promocja jest integralną częścią systemu komunikacji przedsiębiorstwa z rynkiem. Obecnie coraz częściej podkreśla się, że promocja to nie tylko przekaz jednokierunkowy polegający na nagłaśnianiu i szerzeniu wiedzy na temat przedsiębiorstwa i jego produktów, lecz także dialog między przedsiębiorstwem a odbiorcami informacji. Dzięki temu, że przepływ informacji jest dwukierunkowy, nabywcy otrzymują wiedzę na temat produktów, oferenci natomiast na temat postaw nabywców wobec ich ofert i wysiłków marketingowych. Z jednej strony sprzyja to znajdywaniu przez nabywców produktów odpowiednich do ich potrzeb, z drugiej zaś ułatwia dostosowanie ofert do oczekiwań klientów [Panasiuk 2005, s. 125, Jaremen 2013, s. 152].

Promocja jest więc działalnością polegającą na komunikowaniu się przedsiębiorstwa turystycznego z rynkiem. Można wyróżnić pięć podstawowych rodzajów tej komunikacji lub - jak to się najczęściej określa - pięć instrumentów promocji, a mianowicie: 
- reklamę, definiowaną jako każdą płatną formę bezosobowej prezentacji produktu przez określonego nadawcę,

- $\quad$ sprzedaż osobista, która jest bezpośrednią (osobistą) prezentacją oferty klientowi (potencjalnemu nabywcy) przez sprzedawcę,

- promocję sprzedaży, określaną jako pobudzanie zainteresowania produktem przez zastosowanie krótkookresowych działań w postaci zachęt (bodźców ekonomicznych) i ekspozycji,

- public relations, tj. planową i systematyczną działalność mającą na celu stworzenie i utrzymanie relacji między przedsiębiorstwem a jego otoczeniem; tworzenie pozytywnego obrazu firmy i produktu,

- marketing bezpośredni, tj. zespół działań oraz środków bezpośredniego $\mathrm{i}$ indywidualnego oddziaływania na klienta w celu doprowadzenia do zawarcia transakcji kupna-sprzedaży; ma wiele form: poczta elektroniczna, telemarketing, marketing elektroniczny, portale, blogi itp. [Mazurkiewicz 2002, s. 288-289, Kruczek i Walas 2004, Huertas 2008, s. 406-408, Pabian 2008, s. 29-32, Parzonko i Piłat 2009, s. 89, Grzegorczyk 2010, s. 27-38, Kotler 2010, s. 546-547, Mruk 2012, s. 269, s. 34, Strzembicki 2012, s. 171].

\section{Zmiany w zakresie form promocji obiektów turystyki wiejskiej}

Jeszcze nie tak dawno wśród kierunków i form promocji skierowanych na pozyskanie nowych klientów do kwater turystyki wiejskiej/agroturystycznych wykorzystywane były najczęściej: publikacja katalogów, udział w targach i giełdach turystycznych krajowych i międzynarodowych, informacja i reklama w środkach masowego przekazu oraz czasopismach turystycznych, uaktywnienie środowiska dziennikarskiego (konferencje prasowe, prezentacja ofert agroturystycznych), imprezy kulturalne i rozrywkowe połączone z prezentacją ofert, konkursy i gry nagradzane pobytami w kwaterach agroturystycznych oraz filmy propagandowe, reklamowe i informacyjne [Drzewiecki 2001, s. 166]. Rzadziej natomiast oferenci omawianych usług stosowali nowoczesne formy przekazu informacji. Publikacje informacyjno-promocyjne były i są dostępne w regionalnych i lokalnych punktach informacji turystycznej, czy też upowszechniane na licznych imprezach plenerowych (targi, festyny, giełdy produktów turystycznych). Najważniejszym tego typu wydarzeniem są Międzynarodowe Targi Turystyki Wiejskiej i Agroturystyki AGROTRAVEL organizowane w Polsce od 2009 roku. 
Preferencje dotyczące wyboru skutecznych form promocji wykorzystywanych przez usługodawców zmieniały się w czasie. Tendencje w zakresie podejmowanych działań informacyjno-promocyjnych przedstawiono w tabeli 1.

Tabela 1

Źródła informacji o obiekcie turystyki wiejskiej/agroturystyki w opinii usługodawców w latach 2003-2012 [\%]

\begin{tabular}{|l|c|c|c|c|}
\hline Źródła informacji & $\begin{array}{c}2003^{*} \\
\mathrm{~N}=383\end{array}$ & $\begin{array}{c}2006^{\star \star} \\
\mathrm{N}=125\end{array}$ & $\begin{array}{c}2010^{\star \star \star} \\
\mathrm{N}=256\end{array}$ & $\begin{array}{c}2012^{\star \star \star \star} \\
\mathrm{N}=800\end{array}$ \\
\hline Wiadomości od znajomych & 25,1 & 7,2 & 3,1 & 77,0 \\
\hline Portale internetowe & 26,4 & 75,2 & 88,7 & 65,4 \\
\hline Ulotki, foldery, katalogi & 51,7 & 23,2 & 32,0 & 25,9 \\
\hline Ogłoszenia w prasie & 17,2 & 21,6 & 5,9 & 14,6 \\
\hline Targi, giełdy turystyczne & 13,1 & 7,2 & 25,4 & 9,8 \\
\hline Wizyta w punkcie informacji turystycznej & - & - & - & 14,8 \\
\hline Wizyta w biurze podróży & - & - & - & 11,1 \\
\hline
\end{tabular}

Badany mógł podać więcej niż jedną odpowiedź.

${ }^{*}$ E. Jachimowicz, K. Krzyżanowska, 2004: Pozarolnicze funkcje gospodarstwa rolniczego na przykładzie jego działalności agroturystycznej, Wydawnictwo SGGW, Warszawa, s. 92-93.

${ }^{\star \star}$ A. Balińska, I. Sikorska-Wolak, 2009: Turystyka wiejska szansą rozwoju wschodnich terenów przygranicznych na przykładzie wybranych gmin, Wydawnictwo SGGW, Warszawa, s. 105.

${ }^{* * *} \mathrm{M}$. Roman, 2014: Ekonomiczno-społeczne uwarunkowania rozwoju agroturystyki w gminach wiejskich województwa podlaskiego, Wydawnictwo Zespołu Szkół Centrum Kształcenia Rolniczego im. Jadwigi Dziubińskiej w Golądkowie, Golądkowo, s. 116.

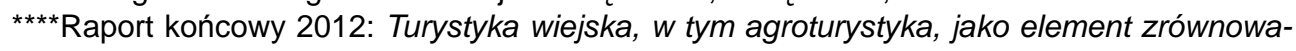
żonego i wielofunkcyjnego rozwoju obszarów wiejskich, kierownik projektu: J. Bański, wykonawca: Agrotec Polska Sp. z o.o., IGP i Z PAN, Warszawa, s. 85.

Źródło: Opracowanie własne na podstawie badań własnych i innych autorów.

Obserwując współczesny rynek turystyczny, można zauważyć zjawisko zmniejszającego się zaufania do tradycyjnych instrumentów promocji oraz coraz większego znaczenia Internetu w docieraniu z ofertą turystyki wiejskiej do klienta. Potwierdzają to zarówno wyniki badań empirycznych przeprowadzonych przez autorkę $^{2}$, jak i zrealizowanych przez innych autorów. Przejawem wykorzystania nowoczesnych technologii jest więc tworzenie stron internetowych gospodarstw agroturystycznych oraz wykorzystanie portali społecznościowych. Największy serwis agroturystyczny prowadzony jest na portalu www.agroturystyka.pl, na którym prezentowane są rekomendowane oferty gospodarstw z całej Polski.

\footnotetext{
${ }^{2}$ Badania empiryczne przeprowadzone zostały w 2003 roku w ramach projektu badawczego nr PO6R 06222 pt. „Pozarolnicze funkcje gospodarstwa rolniczego” finansowanego przez KBN. Objęto nimi 383 rolników prowadzących działalność agroturystyczną na terenie siedmiu województw: lubelskiego, lubuskiego, małopolskiego, pomorskiego, śląskiego, świętokrzyskiego i warmińsko-mazurskiego.
} 
Usługodawcy uczestniczący w badaniach empirycznych uznali również, że rekomendacje znajomych zadowolonych $\mathrm{z}$ pobytu $\mathrm{w}$ obiekcie turystyki wiejskiej/agroturystyki są tanią i skuteczną formą promocji oferty.

Kolejną kwestią podjętą w badaniach była ocena źródeł informacji preferowanych przez turystów wypoczywających na wsi, co przedstawiono w tabeli 2.

\section{Tabela 2}

Źródła informacji o możliwościach wypoczynku na wsi preferowane przez turystów w latach 1997-2013 [\%]

\begin{tabular}{|c|c|c|c|c|c|c|c|}
\hline Źródła informacji & $\begin{array}{c}1997^{*} \\
N=349\end{array}$ & $\begin{array}{c}2001^{*} \\
N=745\end{array}$ & $\begin{array}{c}2003^{*} \\
N=413\end{array}$ & $\begin{array}{c}2006^{* *} \\
N=520\end{array}$ & $\begin{array}{l}2010^{* \star *} \\
N=226\end{array}$ & $\begin{array}{l}2012^{\star \star \star *} \\
N=761\end{array}$ & $\begin{array}{c}2013^{\star \star \star \star \star \star ~} \\
N=122\end{array}$ \\
\hline $\begin{array}{l}\text { Wiadomości } \\
\text { od znajomych }\end{array}$ & 40,1 & 47,2 & 42,2 & 51,9 & 34,5 & 39,2 & 46,0 \\
\hline $\begin{array}{l}\text { Portale } \\
\text { internetowe }\end{array}$ & - & 5,0 & 20,2 & 24,2 & 58,4 & 58,0 & 92,0 \\
\hline $\begin{array}{l}\text { Ulotki, foldery, } \\
\text { katalogi }\end{array}$ & 15,0 & 19,5 & 12,7 & 1,5 & 4,0 & 2,4 & - \\
\hline $\begin{array}{l}\text { Ogłoszenia } \\
\text { w prasie }\end{array}$ & 19,3 & 13,7 & 14,4 & \multirow{3}{*}{3,5} & 0,9 & 1,2 & 25,0 \\
\hline $\begin{array}{l}\text { Audycje } \\
\text { telewizyjne }\end{array}$ & 12,8 & 2,8 & 2,9 & & - & - & 35,0 \\
\hline Audycje radiowe & 1,5 & 1,1 & 2,7 & & - & - & - \\
\hline $\begin{array}{l}\text { Targi i giełdy } \\
\text { turystyczne }\end{array}$ & 7,3 & 2,8 & 2,2 & - & 2,2 & 0,4 & 3,0 \\
\hline $\begin{array}{l}\text { Wizyta w punkcie } \\
\text { informacji } \\
\text { turystycznej lub } \\
\text { biurze podróży }\end{array}$ & 1,2 & 2,0 & 0,2 & - & - & 3,7 & 9,0 \\
\hline
\end{tabular}

Badany mógł podać więcej niż jedną odpowiedź.

*L. Strzembicki, 2005: Wypoczynek w gospodarstwach wiejskich w opinii turystów, [w:] Turystyka wiejska a rozwój i współpraca regionów, Prace Naukowo-Dydaktyczne Państwowej Szkoły Zawodowej w Krośnie, z. 15, s. 32.

${ }^{* \star}$ A. Balińska, I. Sikorska-Wolak, 2009: Turystyka wiejska szansą rozwoju wschodnich terenów przygranicznych na przykładzie wybranych gmin, Wydawnictwo SGGW, Warszawa, s. 108.

${ }^{* * *}$ M. Roman, 2014: Ekonomiczno-społeczne uwarunkowania rozwoju agroturystyki w gminach wiejskich województwa podlaskiego, Wydawnictwo Zespołu Szkół Centrum Kształcenia Rolniczego im. Jadwigi Dziubińskiej w Golądkowie, Golądkowo, s. 116.

****J. Zawadka, 2013: Tendencje zmian w zachowaniach turystycznych osób wypoczywających na wsi, [w:] Komunikowanie i doradztwo w turystyce wiejskiej, Wydawnictwo SGGW, Warszawa, s. 116.

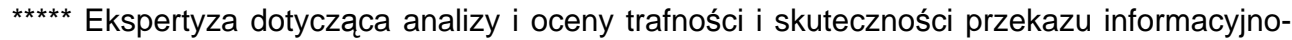
-promocyjnego $w$ kontekście potrzeb informacyjnych z zakresu turystyki wiejskiej, w tym agroturystyki, s. 90, www.bip.minrol.gov.pl (data opublikowania: 20.08.2013).

Źródło: Opracowanie własne na podstawie badań innych autorów. 
Z badań Strzembickiego [2012, s. 177] wynika, że w 1997 roku tylko znikoma część turystów kontaktowała się z obiektami turystyki wiejskiej przez Internet, obecnie natomiast ponad $90 \%$ rezerwacji usług turystycznych na polskiej wsi realizowanych jest $\mathrm{z}$ wykorzystaniem tego medium. Internet jako ważne medium promocyjne oferuje bogaty zestaw środków oddziaływania na potencjalnych nabywców usług turystyki wiejskiej. Najbardziej rozpowszechnioną formą promocji w Internecie są strony www. Ich istotna rola wynika nie tylko z możliwości promocji usług obiektów turystyki wiejskiej poprzez zamieszczanie różnych komunikatów z zakresu reklamy, marketingu bezpośredniego, promocji sprzedaży i public relations. Poprzez strony www można skutecznie kształtować wizerunek obiektów turystyki wiejskiej, stowarzyszeń i federacji, komunikować się z klientem i innymi podmiotami, budować trwałe związki z konsumentami usług oraz ich lojalność. W związku z tym należy zadbać o ich jakość, użyteczność i funkcjonalność [Law i Buhalis 2010, s. 297]. Z informacji zawartych w ekspertyzie dotyczącej analizy i oceny trafności i skuteczności przekazu informacyjno-promocyjnego w kontekście potrzeb informacyjnych z zakresu turystyki wiejskiej, w tym agroturystyki [Ekspertyza 2013, s. 89] wynika, że najistotniejszą informacją umieszczoną na portalu internetowym powinna być cena oraz opłaty dodatkowe wraz ze wskazaniem, co wchodzi w cenę oferty. Na drugim miejscu uplasowały się zdjęcia i filmy, które powinny przedstawiać regiony, wsie i gospodarstwa. Opis okolicy i historia regionu znalazły się na dalszych pozycjach w rankingu. Według respondentów, w każdym regionie powinny być opisane walory przyrodnicze, szlaki turystyczne, zabytki i skanseny, szlaki i wioski tematyczne, imprezy i inne oferowane turystyczne produkty pakietowe oraz sieciowe. Ponadto na portalu internetowym powinna być zamieszczona informacja dotycząca warunków lokalowych wraz ze wskazaniem liczby pokoi, dostępności i odpłatności miejsc parkingowych, dostępu do Internetu i innych udogodnień. Obecna powinna być również informacja o możliwości zabrania zwierząt. Wskazane powinny być wszelkie atrakcje i produkty turystyczne, a także możliwości aktywnego wypoczynku, dostęp do sprzętu sportowego. Istotne są też informacje na temat dojazdu (mapy dojazdu, możliwość przyjechania komunikacją zbiorowa). Opisy ofert powinny również zawierać informację na temat dostępności sklepów i punktów medycznych.

Drugim ważnym źródłem informacji o możliwościach wypoczynku na wsi w latach 1997-2013 były polecenia znajomych zadowolonych z pobytu. Korzystał z nich co drugi badany turysta zarówno 15 lat temu, jak i obecnie.

Spróbujmy odpowiedzieć na pytanie, czy formy promocji wykorzystywane przez usługodawców są dostosowane do potrzeb i oczekiwań turystów. Informacje na ten temat przedstawiono w tabeli 3 . 
Tabela 3

Stopień dostosowania działań informacyjno-promocyjnych z zakresu turystyki wiejskiej/ lagroturystyki podejmowanych przez usługodawców do potrzeb i oczekiwań turystów w latach 2003 i 2012 [\%]

\begin{tabular}{|l|c|c|c|c|}
\hline \multirow{2}{*}{$\begin{array}{l}\text { Działania informacyjno- } \\
\text {-promocyjne }\end{array}$} & \multicolumn{2}{|c|}{2003} & \multicolumn{2}{c|}{2012} \\
\cline { 2 - 5 } & $\begin{array}{c}\text { Usługodawcy } \\
\mathrm{N}=383^{\star}\end{array}$ & $\begin{array}{c}\text { Turyści } \\
\mathrm{N}=413^{\star \star}\end{array}$ & $\begin{array}{c}\text { Usługodawcy } \\
\mathrm{N}=800^{\star \star \star}\end{array}$ & $\begin{array}{c}\text { Turyści } \\
\mathrm{N}=761^{\star \star \star \star}\end{array}$ \\
\hline Wiadomości od znajomych & 25,1 & 47,2 & 77,0 & 39,2 \\
\hline Portale internetowe & 26,4 & 20,2 & 65,4 & 58,0 \\
\hline Ulotki, foldery, katalogi & 51,7 & 12,7 & 25,9 & 2,4 \\
\hline Ogłoszenia w prasie & 17,2 & 14,4 & 14,6 & 1,2 \\
\hline Targi, giełdy turystyczne & 13,1 & 2,2 & 9,8 & 0,4 \\
\hline $\begin{array}{l}\text { Punkt informacji turystycznej } \\
\text { lub biuro podróży }\end{array}$ & - & 0,2 & 25,9 & 3,7 \\
\hline
\end{tabular}

Badany mógł podać więcej niż jedną odpowiedź.

${ }^{\star}$ E. Jachimowicz, K. Krzyżanowska, 2004: Pozarolnicze funkcje gospodarstwa rolniczego na przykładzie jego działalności agroturystycznej, Wydawnictwo SGGW, Warszawa, s. 92-93.

**L. Strzembicki, 2005: Wypoczynek w gospodarstwach wiejskich w opinii turystów, [w:] Turystyka wiejska a rozwój i współpraca regionów, Prace Naukowo-Dydaktyczne Państwowej Szkoły Zawodowej w Krośnie, z. 15, s. 32.

${ }^{* * *}$ Raport końcowy, 2012: Turystyka wiejska, w tym agroturystyka, jako element zrównoważonego i wielofunkcyjnego rozwoju obszarów wiejskich, kierownik projektu: J. Bański, wykonawca: Agrotec Polska Sp. z o.o., IGPiZ PAN, Warszawa, s. 85.

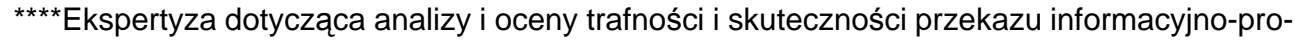
mocyjnego w kontekście potrzeb informacyjnych z zakresu turystyki wiejskiej, w tym agroturystyki, s. 90, www.bip.minrol.gov.pl (data opublikowania: 20.08.2013).

Źródło: Opracowanie własne na podstawie badań własnych i innych autorów.

Formy promocji wykorzystywane przez usługodawców nie były w pełni dostosowane do potrzeb i oczekiwań turystów zarówno w 2003, jak i 2012 roku. Dziesięć lat temu najważniejszym źródłem informacji o możliwościach wypoczynku $\mathrm{w}$ gospodarstwie agroturystycznym były rekomendacje krewnych i znajomych, a nie wydawnictwa promocyjne w formie katalogów, folderów czy informatorów, które najczęściej stosowali usługodawcy w 2012 roku. Obecnie najważniejszym źródłem informacji o możliwościach wypoczynku na wsi jest dla badanych turystów Internet, a usługodawcy dużą uwagę przywiązywali do pozytywnych opinii wyrażonych przez zadowolonych gości z pobytu w obiektach turystyki wiejskiej. Co czwarty badany usługodawca promował przygotowaną ofertę, wykorzystując do tego celu wydawnictwa promocyjne w formie ulotek, katalogów, folderów czy informatorów, z których sporadycznie korzystali turyści. 


\section{Podsumowanie i wnioski}

1. Z przeprowadzonej analizy wynika, że coraz częściej tradycyjne formy komunikacji marketingowej zastępowane są przez Internet. W 1997 roku tylko znikoma część turystów kontaktowała się z obiektami turystyki wiejskiej przez Internet, a obecnie ponad 4/5 rezerwacji usług turystycznych na polskiej wsi realizowanych jest $\mathrm{z}$ wykorzystaniem tego medium. Drugim ważnym źródłem informacji o możliwościach wypoczynku na wsi w latach 1997-2013 były rekomendacje znajomych zadowolonych z pobytu. Korzystał z nich co drugi badany turysta zarówno 15 lat temu, jak i obecnie.

2. Formy promocji wykorzystywane przez usługodawców nie były w pełni dostosowane do potrzeb i oczekiwań turystów zarówno w 2003, jak i w 2012 roku. Dziesięć lat temu najważniejszym źródłem informacji o możliwościach wypoczynku w gospodarstwie agroturystycznym były rekomendacje krewnych i znajomych, a nie wydawnictwa promocyjne w formie katalogów, folderów czy informatorów, które najczęściej stosowali usługodawcy. W 2012 roku najważniejszym źródłem informacji o możliwościach wypoczynku na wsi był dla badanych turystów Internet, a usługodawcy dużą uwagę przywiązywali do pozytywnych opinii wyrażonych przez zadowolonych gości odpoczywających w obiektach turystyki wiejskiej. Dlatego ważne jest, aby rolnicy i mieszkańcy wsi dbali o wysoki standard stron internetowych, spełniając tym samym oczekiwania turystów. Fachową pomoc w tym zakresie usługodawcy mogą uzyskać kontaktując się z doradcami ośrodków doradztwa rolniczego czy przedstawicielami stowarzyszeń agroturystycznych.

\section{Literatura}

BALIŃSKA A.,SIKORSKA-WOLAK I., 2001: Turystyka wiejska szansq rozwoju wschodnich terenów przygranicznych na przykładzie wybranych gmin, Wydawnictwo SGGW, Warszawa.

DRZEWIECKI M., 2001: Podstawy agroturystyki, Oficyna Wydawnicza Ośrodka Postępu Organizacyjnego Sp. z o.o., Bydgoszcz.

Ekspertyza dotyczqca analizy i oceny trafności i skuteczności przekazu informacyjno-promocyjnego $w$ kontekście potrzeb informacyjnych z zakresu turystyki wiejskiej, w tym agroturystyki, www.bip.minrol.gov.pl (data opublikowania: 20.08.2013).

FLANINGAN S., BLACSTOCK K., HUNTER C., 2010: Agritourism from the Perspective of Providers and Visitors: A Typology-Based Study, ,Tourism Management” 2014, vol. 40.

GRZEGORCZYK A., 2010: Reklam, PWE, Warszawa.

HUERTAS A., 2008: Public Relations and Tourism: Fighting for the Role of Public Relations in Tourism, „Public Relations Review”, vol. 34, s. 406-408. 
JACHIMOWICZ E., KRZYŻANOWSKA K., 2004: Pozarolnicze funkcje gospodarstwa rolniczego na przykładzie jego działalności agroturystycznej, Wydawnictwo SGGW, Warszawa.

JAREMEN D., 2013: Promocja jako instrument marketingu $w$ turystyce i rekreacji, [w:] Marketing w turystyce i rekreacji, red. naukowa A. Panasiuk, Wydawnictwo Naukowe PWN, Warszawa.

KOTLER Ph., 1994: Marketing. Analiza, planowanie, wdrażanie i kontrola, Wydawnictwo Gebethner i S-ka, Warszawa.

KRUCZEK Z., WALAS B., 2004: Promocja i informacja turystyczna, Wydawnictwo Proksenia, Kraków.

LAW R., BUHALIS S.Qi.D., 2010: Progress in Tourism Management: A Review of Website Evaluation in Tourism Research, „Tourism Management” vol. 31, s. 297.

MAZURKIEWICZ L., 2002: Planowanie marketingowe w przedsiębiorstwie turystycznym, PWE, Warszawa.

MRUK H., 2012: Marketing. Satysfakcja klienta i rozwój przedsiębiorstwa, Wydawnictwo Naukowe PWN, Warszawa.

PABIAN A., 2008: Promocja. Nowoczesne środki i formy, Wydawnictwo Difin, Warszawa.

PANASIUK A., 2005: Marketing usług turystycznych, Wydawnictwo Naukowe PWN, Warszawa.

PARZONKO A.J., PIŁAT M., 2009: Internet w rozwoju polityki promocji hoteli, [w:] Społeczne uwarunkowania rozwoju obszarów wiejskich, red. naukowa K. Krzyżanowska, Wydawnictwo SGGW, Warszawa.

Raport końcowy, 2012: Turystyka wiejska, w tym agroturystyka, jako element zrównoważonego i wielofunkcyjnego rozwoju obszarów wiejskich, Kierownik projektu: J. Bański, wykonawca: Agrotec Polska Sp. z o.o., IGPiZ PAN, Warszawa.

Raport „Rolnictwo i gospodarka żywnościowa w Polsce w 2012 r.” przygotowany na zlecenie MR i RW, red. zbiorowa Instytut Ekonomiki Rolnictwa i Gospodarki Żywnościowej, Warszawa 2013.

ROMAN M., 2014: Ekonomiczno-spoleczne uwarunkowania rozwoju agroturystyki w gminach wiejskich województwa podlaskiego, Wydawnictwo Zespołu Szkół Centrum Kształcenia Rolniczego im. Jadwigi Dziubińskiej w Golądkowie, Golądkowo, s. 116.

SIKORA J., 2013: Rynek promocji w turystyce wiejskiej, [w:] Komunikowanie i doradztwo w turystyce wiejskiej, red. naukowa K. Krzyżanowska, Wydawnictwo SGGW, Warszawa.

SIKORA J., 2012: Agroturystyka. Przedsiębiorczość na obszarach wiejskich, Wydawnictwo C.H. Beck, Warszawa.

STANTON W.J., 1975: Fundamentals of Marketing, Mc Graw-Hill, New York.

STRZEMBICKI L., 2012: Promocja turystyki wiejskiej w Polsce - doświadczenia i wyzwania, [w:] Wiejski produkt turystyczny. Doświadczenia i wyzwania, red. naukowa J. Majewski, Wydawnictwo Kieleckie Towarzystwo Edukacji Ekonomicznej, Kielce.

STRZEMBICKI L., 2005: Wypoczynek $w$ gospodarstwach wiejskich $w$ opinii turystów, [w:] Turystyka wiejska a rozwój i wspólpraca regionów, Prace Naukowo-Dydaktyczne Państwowej Szkoły Zawodowej w Krośnie, z. 15, s. 32.

TEW Ch., BARBIERI C., 2012: The Perceived Benefits of Agritourism: The Provider's perspective. „Tourism Management”, vol. 33, s. 215-224. 
ZAWADKA J., 2010: Ekonomiczno-spoleczne determinanty rozwoju agroturystyki na Lubelszczyźnie (na przykładzie wybranych gmin wiejskich), Wydawnictwo SGGW, Warszawa.

ZAWADKA J., 2013: Tendencje zmian w zachowaniach turystycznych osób wypoczywajacych na wsi, [w:] Komunikowanie i doradztwo w turystyce wiejskiej, Wydawnictwo SGGW, Warszawa.

www.farmer.pl/fakty/polska/w-polsce-sa-373-gospodarstwa-posiadajace-ponad-tysiacha,40756.html (data dostępu: 24.02.2014).

\title{
Trends in the field of effective information and promotion activities in rural tourism
}

\begin{abstract}
The aim of the study was to present the changes in the number of lodgings in the years 1993-2013, trends related to forms of promotion used by rural tourism service providers, as well as information sources preferred by tourists resting in the countryside in the years 1997-2013. Additionally, the research covers the information and promotion methods used by service providers to meet the needs and expectations of customers. The data comes from empirical studies conducted both by the author and other authors from different academic centres in Poland, secondary data from the expert opinions provided by different institutions, and literature. The analysis shows that the forms of promotion used by the service providers were not fully adapted to the needs and expectations of tourists, both in 2003 and in 2012. Ten years ago, the most important source of information about holiday stay on a farm were the recommendations of relatives and friends, not promotional literature mostly used by service providers. Nowadays, the most important source of information about recreation in the countryside for surveyed tourists was the Internet, while the service providers' great attention was given to the positive views expressed by satisfied guests resting in objects of rural tourism.
\end{abstract}


